\title{
THE THERMAL EFFECT ASSOCIATED WITH CO, LASER GINGIVECTOMY OF TISSUES SURROUNDING PLASMA COATED TITANIUM IMPLANTS. A PRELIMINARY STUDY
}

W.A. Mahmood, A.C. Watkinson, J. Rooney. The thermal effect associated with $\mathrm{CO}_{2}$ laser gingivectomy of tissues surrounding plasma coated titanium implants. A preliminary study. Annal Dent Univ Malaya 2000; 7: $16-21$.

\section{ABSTRACT}

The $\mathrm{CO}_{2}$ laser has been actively used clinically for soft tissue surgery. The advantages have been widely acknowledged. In implant related tissue surgery, the use of $\mathrm{CO}_{2}$ laser has been debated on whether the heat generated during the procedure would be detrimental to the bone thus losing the implants through disosseointegration.

In this preliminary work, $\mathrm{CO}_{2}$ laser was used to perform a simulated gingivectomy of tissue surrounding plasma coated titanium implants. The purpose was to observe the pattern of heat generated at different levels of the implant body. The safe power range and standard precaution was also identified. The results suggested that power output between 6 Watt to 8 Watt in repeated pulsed mode with duration of 5 seconds is considered safe. With this mode the operator would have a better heat control in the operation.

Key words: $\mathrm{CO}_{2}$ laser, thermal changes, implants, peri implant gingivectomy.

\section{INTRODUCTION}

Implantology has been an area of considerable interest for dental application of laser technology. Walsh provided an overview of the use of lasers in laboratory and clinical techniques used in implantology. Principles for the safe use of lasers were outlined. However, heat generation has been one potential complication of laser treatment especially in peri implant tissues where this could result in subsequent implant failure. Previous studies have demonstrated that heat may induce bone resorption and minimize the regenerative capacity of bone (2). Several in vitro studies (3-5) using carbon dioxide $\left(\mathrm{CO}_{2}\right)$ laser around implants have demonstrated temperature changes. The site which has the highest temperature rise is the collar and is the area where the greatest initial bone loss occurs during the first year (3). While another study (4) showed that significant heat $\left(>50^{\circ} \mathrm{C}\right)$ could be generated on the lateral surface of a plasma-sprayed hydroxyapatite HA coated titanium dental implant when laser energy was applied to the coverscrew. $\operatorname{Gantz}(5)$, on the basis of his in vitro study, claimed that a $\mathrm{CO}_{2}$ laser produced minimal temperature changes when used around 2 different types of implant surfaces using the appropriate power densities.

\section{Original Article}

W.A. Mahmood ${ }^{1}$, A.C. Watkinson ${ }^{2}$ and
J. Rooney
'Department of Prosthetics
Faculty of Dentistry, University of Malaya
50603 Kuala Lumpur
2,3epartment of Oral and Dental Science
Division of Restorative Dentistry
Bristol Dental School and Hospital
Lower Maudlin Street
Bristol BSI $2 L Y$, UK.
Corresponding author - W.A. Mahmood

$\mathrm{CO}_{2}$ laser energy at $1060 \mathrm{~nm}$ is not well absorbed by a metallic surface which is capable of reflecting such energy, reducing the potential for damage to the metallic implant surface and for thermal injury (via conduction) to underlying tissues (1). The neodymium: yttriumaluminium-garnet (Nd; YAG) laser is not recommended for use around implants as this poses considerable risks for damage to the underlying tissues as well as possible surface alterations of titanium implants $(1,6,8)$.

Different types of implants have been used in previous work such as pure threaded titanium implants $(5,8)$ and plasma sprayed HA (4-6). Plasma sprayed titanium (6) was used using ND;YAG laser and to date no work has been reported using $\mathrm{CO}_{2}$ lasers.

Based on these experiences, $\mathrm{CO}_{2}$ lasers are generally considered safe for implants and have been recommended for implant uncovering procedures.

Laser gingivectomy was first attempted by Pick (9). Soft tissue reaction post operatively was favourable and the advantages included lack of haemorrage providing a dry operating field, sterilization of the surgical area, minimal post operative discomfort and reduced operative time (9). This has led to an increasing acceptance by both practitioners and patients. Until now lasers have been effectively used to perform laser gingivectomies on patients with tissue overgrowth or hyperplasia, but laser gingivectomy of peri implant tissues has yet to be explored.

The aim of this in vitro study was to determine the amount and pattern of heat generated within the body of a titanium plasma sprayed ITI dental implant during laser gingivectomy and to select a range of wattage and exposure time that is permissible for such procedure. This study would differ from the previous work as the implants used are the open mucosal system, in which the primary part is inserted such that the top remains about $3 \mathrm{~mm}$ above the bone crest. 


\section{MATERIALS AND METHOD}

Five titanium plasma coated ITI implants were placed into a section of resected pig mandible. Fenestrations were made at the apical and mid point of the implants (Fig 1) for the placement of thermocouple tips.

The Sharplan $1020 * \mathrm{CO}_{2}$ laser with a diameter tip of $1.0 \mathrm{~mm}$. was used. The articulated armbeam delivery system offers excellent ability to manoeuver, adequate working distance and light full wrist motion.

Two mode of operations were selected as follows:

1) Continous wave mode wherein the $\mathrm{CO}_{2}$ laser output beam is continously emitted for as long as the footswitch is depressed. The selection of the output power was $2 \mathrm{~W}$ to $8 \mathrm{~W}$ and the range of emission duration of 2,5 and 8 seconds.

2) Repeated pulse mode, with power output range from $4 \mathrm{~W}$ to $8 \mathrm{~W}$ and emission duration of 5,8 and 10 seconds. The pulse mode provides an intermittent emission duration with end pulse of 0.02 seconds. This emission of $\mathrm{CO}_{2}$ laser beam as a train of pulses for as long as the footswitch is depressed. The pulses are delivered at set repetition rates determined by pulse duration setting.

Power (Watt) and exposure time $\left(t^{1}\right.$ and $\left.t^{2}\right)$ selected were based on suggestions from previous studies for tissue excision and second stage implants surgery $(3,8)$.

The tip of thermocouples were placed at the reference points and this was attached to meters. Thermocouples were provided with recording strips with the reading recorded at every 2 seconds. The temperatures of the reference points i.e the apical and the mid point of the implant body were read prior to laser exposure and were taken as initial temperatures $\left(t^{1}\right)$. Following each laser exposure the maximum temperature recorded (on the paper strips) was taken as the post lasing temperature $\left(\mathrm{t}^{2}\right)$. In this study, temperature changes or the thermal increment was calculated as the difference between the two measurements. $\left(\mathrm{t}^{2}-\mathrm{t}^{1}\right)$. The laser tip was directed in a non contact position on the soft tissue surrounding the implant. Since the coronal part of the implant was exposed during the whole procedure, it was necessary to make sure that the tissues were frequently moistened. The procedure was to incise the soft tissue simulating gingivectomy at different power outputs and durations of laser beam delivary. After each application, the tissue and the implant were allowed to cool down with air spray.

All the readings from the termocouple paper strip were compiled according to the pre and post lasing temperatures. ( $\mathrm{t}^{1}$ and $\mathrm{t}^{2}$ )

\section{RESULTS}

In general, thermal changes was observed. This energy from the $\mathrm{CO}_{2}$ laser generated the heat to the soft tissues. This energy was then conducted to the implant body via the surrounding tissues when being lased. The coronal part of the implant exhibited the highest temperature change as compared to the mid point and the apical part of the implant body which demonstrated less heat.

Tables $1 \mathrm{a}$ and $\mathrm{b}$ showed the results of the initial work on comparing the heat distribution at 3 reference points of the implant body. There was a pattern for heat to be reduced as it travelled towards the apex in the 2 modes (repeat pulse and continous mode).

From these results, it was decided that only 2 reference points i.e the coronal and mid point of the implant body were relevant to be used to record the readings for the following study (Fig. 1).

Tables 2 and 3 showed the different power output and duration for continous and repeated pulse mode.

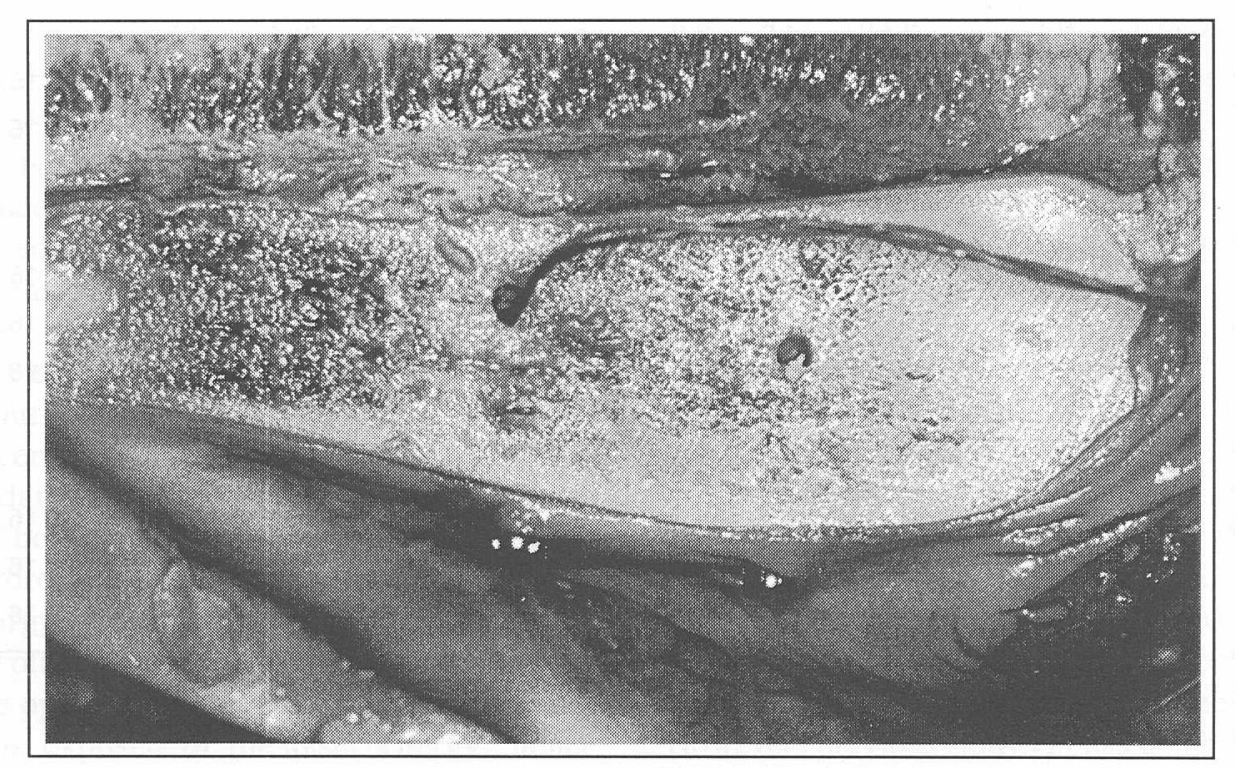

Figure 1: The resected part of the pig mandible.

The 2 reference points connected to the thermocouple. 
Table 1a. Temperature changes and increment pattern at different levels of the implant body at duration time of 5 seconds

\section{Continous mode}

\begin{tabular}{|c|c|c|c|c|c|c|c|c|c|}
\hline \multirow{3}{*}{$\begin{array}{l}\text { Power Output } \\
\text { (watt) }\end{array}$} & \multicolumn{9}{|c|}{ IMPLANT BODY $t\left(C^{\circ}\right)$} \\
\hline & \multicolumn{3}{|c|}{ CORONAL } & \multicolumn{3}{|c|}{ MID POINT } & \multicolumn{3}{|c|}{ APICAL } \\
\hline & $t^{1}$ & $t^{2}$ & $\left(t^{2}-t^{1}\right)$ & $t^{1}$ & $t^{2}$ & $\left(t^{2}-t^{1}\right)$ & $t^{1}$ & $t^{2}$ & $\left(t^{2}-t^{1}\right)$ \\
\hline $4 W$ & 16.8 & 30.2 & 13.2 & 13.9 & 15.2 & 1.3 & 14.2 & 15.8 & 0.8 \\
\hline $6 \mathrm{~W}$ & 16.5 & 44.0 & 27.5 & 14.3 & 19.0 & 4.7 & 15.0 & 16.5 & 1.5 \\
\hline $8 W$ & 16.5 & 53.1 & 36.6 & 15.5 & 21.8 & 6.3 & 15.2 & 17.0 & 1.8 \\
\hline
\end{tabular}

Table $1 b$.

Repeat pulse mode

\begin{tabular}{|c|c|c|c|c|c|c|c|c|c|}
\hline \multirow{3}{*}{$\begin{array}{l}\text { Power Output } \\
\text { (watt) }\end{array}$} & \multicolumn{9}{|c|}{ IMPLANT BODY t $\left(\mathrm{C}^{\circ}\right)$} \\
\hline & \multicolumn{3}{|c|}{ CORONAL } & \multicolumn{3}{|c|}{ MID POINT } & \multicolumn{3}{|c|}{ APICAL } \\
\hline & $t^{1}$ & $t^{2}$ & $\left(t^{2}-t^{1}\right)$ & $t^{1}$ & $t^{2}$ & $\left(t^{2}-t^{1}\right)$ & $t^{1}$ & $t^{2}$ & $\left(t^{2}-t^{1}\right)$ \\
\hline $4 \mathrm{~W}$ & 17.0 & 21.5 & 4.5 & 15.7 & 17.0 & 1.3 & 15.8 & 16.1 & 0.3 \\
\hline $6 \mathrm{~W}$ & 17.0 & 24.8 & 7.8 & 16.5 & 17.9 & 1.4 & 16.5 & 17.0 & 0.5 \\
\hline $8 W$ & 18.2 & 34.1 & 15.9 & 16.4 & 19.4 & 3.0 & 16.2 & 17.0 & 0.8 \\
\hline
\end{tabular}

Table 2. Simulated gingivectomy procedure at different power output and duration

\section{CONTINOUS MODE}

\begin{tabular}{|c|c|c|c|c|c|c|}
\hline \multirow[t]{2}{*}{$t\left(C^{\circ}\right)$} & \multicolumn{3}{|c|}{ CORONAL } & \multicolumn{3}{|c|}{ MID POINT } \\
\hline & $t^{\prime}$ & $t^{2}$ & $\left(t^{2}-t^{1}\right)$ & $t^{1}$ & $t^{2}$ & $\left(t^{2}-t^{1}\right)$ \\
\hline \multicolumn{7}{|l|}{$2 W$} \\
\hline $2 \mathrm{sec}$ & 13.6 & 20.0 & 6.4 & 13.0 & 13.6 & 0.6 \\
\hline $5 \mathrm{sec}$ & 14.4 & 22.3 & 7.9 & 13.2 & 14.1 & 0.9 \\
\hline $8 \mathrm{sec}$ & 15.7 & 25.2 & 9.5 & 13.3 & 14.4 & 1.1 \\
\hline \multicolumn{7}{|l|}{$4 W$} \\
\hline $2 \mathrm{sec}$ & 16.5 & 22.0 & 5.5 & 13.7 & 14.4 & 0.7 \\
\hline $5 \mathrm{sec}$ & 16.8 & 30.2 & 13.2 & 13.9 & 15.2 & 1.3 \\
\hline $8 \mathrm{sec}$ & 14.8 & 31.3 & 16.5 & 14.0 & 17.0 & 3.0 \\
\hline \multicolumn{7}{|l|}{$6 W$} \\
\hline $2 \mathrm{sec}$ & 16.5 & 23.7 & 7.2 & 14.0 & 18.2 & 4.2 \\
\hline $5 \mathrm{sec}$ & 16.5 & 44.0 & 27.5 & 14.3 & 19.0 & 4.7 \\
\hline $8 \mathrm{sec}$ & 16.0 & 52.3 & 36.3 & 14.4 & 19.2 & 4.8 \\
\hline \multicolumn{7}{|l|}{$8 W$} \\
\hline $2 \mathrm{sec}$ & 16.6 & 24.0 & 7.4 & 15.3 & 20.6 & 5.3 \\
\hline $5 \mathrm{sec}$ & 16.5 & 53.1 & 36.6 & 15.5 & 21.8 & 6.3 \\
\hline $8 \mathrm{sec}$ & 16.1 & 57.9 & 41.8 & 15.8 & 22.5 & 6.7 \\
\hline
\end{tabular}

Table 3. Simulated gingivoplasty procedure

REPEATED PULSED MODE

\begin{tabular}{|c|c|c|}
\hline \multirow{2}{*}{$t\left(C^{\circ}\right)$} & CORONAL & MID POINT \\
\hline & $t^{2} \quad\left(\begin{array}{ll}\left.t^{2}-t^{1}\right)\end{array}\right.$ & $\left(t^{2}-t^{1}\right)$ \\
\hline
\end{tabular}

\section{W}

$\begin{array}{lllllll}5 \mathrm{sec} & 17.0 & 21.5 & 4.5 & 15.7 & 17.0 & 1.3 \\ 8 \mathrm{sec} & 16.6 & 21.6 & 5 & 15.3 & 16.6 & 1.3 \\ 10 \mathrm{sec} & 17.2 & 23.2 & 6.0 & 16.3 & 17.6 & 1.3\end{array}$

$10 \mathrm{sec}$

$\begin{array}{lll}16.5 & 17.9 & 1.4\end{array}$

$5 \sec$

$8 \mathrm{sec}$

$\begin{array}{lll}17.0 & 24.8 & 7.8\end{array}$

$\begin{array}{lll}16.5 & 18.0 & 1.5\end{array}$

$10 \mathrm{sec}$

$\begin{array}{lll}16.7 & 27.8 & 11.1\end{array}$

$\begin{array}{lll}16.3 & 17.8 & 1.5\end{array}$

\section{$8 W$}

$5 \mathrm{sec}$

$\begin{array}{lll}17.6 & 29.8 & 12.2\end{array}$

$\begin{array}{lll}16.0 & 18.3 & 2.3\end{array}$

$8 \mathrm{sec}$

$\begin{array}{lll}18.2 & 34.1 & 15.9\end{array}$

$\begin{array}{lll}16.4 & 19.4 & 3\end{array}$

$10 \mathrm{sec}$

$\begin{array}{lll}17.8 & 37.4 & 19.6\end{array}$

$\begin{array}{lll}16.4 & 20.0 & 3.6\end{array}$ 
The highest temperature noted was $57.9^{\circ} \mathrm{C}$ giving an increment of $41.8^{\circ} \mathrm{C}$. This was achieved when using the continous mode at power output of $8 \mathrm{~W}$ for 8 seconds. However with the pulse mode at the same power output and duration, it resulted in a much lower temperature increment of $15.9^{\circ} \mathrm{C}$ with the highest temperature of $34.1^{\circ} \mathrm{C}$. This showed that lasing the tissue with continous mode doubled the amount of heat that was produced when using repeated pulse mode (Tab 4).

In both types of operating beam mode, there was a relative increment between power output and duration of irradiation with the thermal increment.

Table 4. The temperature increment for continous and pulse mode at different power output and duration

\begin{tabular}{lll}
\hline \multirow{2}{*}{$\begin{array}{c}\text { Power Output } \\
\text { (watt) }\end{array}$} & \multicolumn{2}{c}{$\begin{array}{c}\text { temperature increment } \\
t\left(C^{\circ}\right)\end{array}$} \\
\cline { 2 - 3 } & Continous mode & Repeat pulse mode \\
\hline $4 \mathrm{~W}$ & 13.2 & \\
$5 \mathrm{sec}$ & 16.5 & 4.5 \\
$8 \mathrm{sec}$ & & 5 \\
& & \\
$6 \mathrm{~W}$ & 27.5 & 7.8 \\
$5 \mathrm{sec}$ & 36.3 & 11.1 \\
$8 \mathrm{sec}$ & & \\
$8 \mathrm{~W}$ & & 12.2 \\
$5 \mathrm{sec}$ & 36.6 & 15.9 \\
$8 \mathrm{sec}$ & 41.8 & \\
\hline
\end{tabular}

\section{DISCUSSION}

In this study, a simulated gingivectomy procedure were performed around 5 transmucosal titanium plasma sprayed ITI implants on a section of resected pig mandible.

The result of this study indicated that, using the $\mathrm{CO}_{2}$ laser at a range between $4 \mathrm{~W}$ (watt) to $8 \mathrm{~W}$ for a duration of 2 seconds under continous mode of operation and $6 \mathrm{~W}$ to $8 \mathrm{~W}$ of pulsed mode with a longer duration of 5 seconds was considered appropriate for the procedure above.

There was evidence of heat generated over the implant body during lasing procedure of the soft tissues covering the cervical part. As $\mathrm{CO}_{2}$ laser is not well absorbed by dark metallic objects, in this case the implants, the beam tend to be reflected from their surface, therefore, it is unlikely that the heat generated from laser energy is directly absorbed to the implants. In contrast to other previous studies (3-5), this study looked into the open mucosal system implant where the coronal part is exposed to the laser energy, hence caution had to be observed especially when focusing the laser beam at the soft tissue. During the lasing procedure, some form of scattering and reflection would be inevitable. Scattering when occured, would cause unfavourable distribution of energy over a large volume of tissues, dissipating the thermal effects as shown in this study. $\mathrm{CO}_{2}$ laser energy is absorbed into the soft tissues which exhibit relatively high water contents, which allows maximum concentration of heat but minimum penetration and therefore is effective on surfaces of the tissues. The amount of absorption is responsible for the thermal effect within the tissues. This heat is then conducted to the body of the implant. The highest temperature produced was at 8 watt after exposing continously for 8 seconds (Table 2).

Two reference points were selected for heat measurement, that is at the coronal part and at the mid point of the implant body. Naturally the temperature and the tissues effects were greatest near the light source. Charred debris from the procedure, absorbs energy and heats up to temperature high enough to cauterize and remove surface tissues. This was observed from the results where the coronal parts exhibited higher temperatures (Tables 1-3). As the tissue depth increases the conducted heat reduces and eventually the heat gets less with the cooling of the site. Hence, the temperature increment at the mid point of the implant range between minimal reading of $0.6^{\circ} \mathrm{C}$ to a maximum of $6.7^{\circ} \mathrm{C}$ which is considered safe without any damaging thermal energy.

The temperature of the sites (coronal and the mid point of the implant body) prior to lasing was taken as the initial temperature. Stabilizing at body temperature of $37^{\circ} \mathrm{C}$ proved impossible as there were constant fluctuations. Temperatures at $47^{\circ} \mathrm{C}$ to $50^{\circ} \mathrm{C}$ were considered physiologically non tolerable (2), based on $37^{\circ} \mathrm{C}$ being that of the oral tissues, and an increment of $10^{\circ} \mathrm{C}$ would cause a temperature of $47^{\circ} \mathrm{C}$. In this case, thermal increment of $10^{\circ} \mathrm{C}$ or greater after exposure will be detrimental. Precaution would be taken to avoid this during clinical procedures. The lasing procedure was controlled by depressing the footswitch. However, the temperature kept increasing even after releasing the footswitch. There was a gradual temperature rise observed from the thermocouple recorded strip at the coronal. It peaked to a maximum reading before gradually declining. The highest temperature was recorded as the post lasing temperature $\left(\mathrm{t}_{2}\right)$. The difference between the pre lasing temperatures $\left(t_{1}\right)$ and post lasing temperatures were noted as the thermal increments $\left(t_{2}-t_{1}\right)$. The maximum temperature recorded on the strip lasted between 2-4 seconds before it started to drop slowly with some fluctuation. This pattern showed to be constant in all the readings from the thermocouple recorded strip. In another study conducted by Oyster et al (3), the highest temperature recorded was observed between 30 to 60 seconds. The difference in the duration would probably be due to the nature of the procedure which took place during uncovering of the implants at the second stage. However, previous study (2) has demonstrated that bone necrosis will only occur at a temperature of $47^{\circ} \mathrm{C}$ which lasted between 1-5 minutes. 
In this experiment, although the increment in temperatures exceeded more than $10^{\circ} \mathrm{C}$, it is very unlikely to cause any immediate pathologic response as the duration was only between 2 to 4 seconds.

Any thermal increment of $10^{\circ} \mathrm{C}$ or greater, but not more than $20^{\circ} \mathrm{C}$ with power outputs between $4 \mathrm{~W}$ to $8 \mathrm{~W}$ is considered safe. This range was found to be comparable to other studies $(3,5)$.

By increasing the power output (wattage) further, what was observed was that the temperature rise to the maximum reading became more rapid. This sudden increase in temperature could be due to the carbonization of the soft tissues. Accumulation of carbonized material produced a very high temperature jump. These findings supported the earlier work by Fisher and Frame (10).

The pattern of each temperature increment was not linear and there was a trend for it to reduce as the wattage increased. The accumulation of charred tissues, forming a carbonized layer on the wound surface appeared to act as a protective covering (10) making further lasing ineffective. This in turn reduced or stopped the penetration of the $\mathrm{CO}_{2}$ laser beam. In order to make the penetration of the beam to be more effective, the charred soft tissues were cleared and cooled off using air spray each time before proceeding. During gingivectomy procedure, the laser was run through 2-3 times to actually cut the tissue. The potential penetration of thermal energy beyond the tissue target site is another major disadvantage of using lasers. Arashiro et al (11) indicated that when using the $\mathrm{CO}_{2}$ laser at $6 \mathrm{~W}$ (continous mode) at least four or five passes within the same incision line have to be made to penetrate $\mathbb{1} .09$ to $1.29 \mathrm{~mm}$ mucosa thickness. With regards to gingivoplasty, they felt it was unlikely that repeated passes of beam would make penetration that could reached to the underlying bone. This relation can be expected as wattage and exposure time has been previously demonstrated to be proportional to the depth of laser incision. Deep penetration is not a problem with $\mathrm{CO}_{2}$ laser, as long as the surface heat transfer is controlled.

In clinical situation, the effect of laser irradiation on tissue has to be accounted for. Tissue response to thermal energy is complex as thermal energy transfer varies between tissues.

In this study, we used the two mode of emissions i.e continous mode and repeated pulse mode. Lasing the tissue in a repeated pulse mode (beam) produced a lower energy as compared to when operating in continous mode. This is because the surrounding tissue would cool between laser pulses, which did not occur with a continous wave laser beam. The general pattern of heat increment transmitted via repeated pulse mode was slower as demonstrated in the present experiment and in other studies (3-5). When compared to continous mode, the increment was only half when pulse mode was utilized.

In this present study, to have several measurements for each evaluation would have meant to repeat each procedure and therefore a bigger sample would have been necessary. After each gingivectomy procedure, the carbonized tissues were scraped off and the subsequent procedure was at a new site. With each new site, the tissues would present variables in depth, texture and thermal energy response. Therefore each repeated procedure was not reproducible as it was not to represent the same condition and in addition thermal energy varies between tissues.

To subject the data to statistical analyses, it was necessary to repeat each of the evaluation several times using a new site each time and hence a bigger sample would have been necessary. As for clinical situation with peri implantitis, the use of $\mathrm{CO}_{2}$ laser would be a safe alternative method providing that the operator choose the right setting and power output as suggested.

\section{CONCLUSION}

1. Heat generation was observed during the $\mathrm{CO}_{2}$ laser gingivectomy procedure.

2. The amount of heat generation during the procedure would depend upon the operator to select the safe modality and power output.

3. This study suggested that the power output between 6 to 8 watt in repeated pulse mode with duration of 5 seconds to be the safe range.

\section{ACKNOWLEDGEMENTS}

The first author would like to thank the staff in Department of Oral and Dental Science, Bristol Dental School and Hospital especially Professor Alan Harrison for allowing her to use all the facilities and material assistance.

\section{REFERENCES}

1. Walsh WJ. The use of lasers in implantology: an overview. J Oral Implantol 1992; 18: 335-40

2. Eriksson AR, Albrektsson T. Temperature threshold levels for heat-induced bone tissue injury: a vital microscopic study in the rabbit. J Prosthet Dent 1983; 50: 101-7.

3. Oyster $\mathrm{K}$, Parker W, Gher $\mathrm{M}$. $\mathrm{CO}_{2}$ Lasers and temperature changes of titanium implants. J Periodontol 1995; 66: 1017-1024

4. Swift JQ, Jenny JE, Hargreaves KN. Heat generation in hydroxyapatite-coated implants as a result of $\mathrm{CO}_{2}$ laser application. Oral Surg Oral Med Oral Pathol 1995; 79: 410-415 
5. Gantz $\mathrm{CH}$. Evaluation of the safety of the $\mathrm{CO}_{2}$ laser used in conjunction with root form implants: A pilot study. J Prosthet Dent 1994; 71: 27-30.

6. Block CM, Mayo JA, Evans GH. Effects of the Nd:YAG dental laser on plasma sprayed and hydroxyapatite coated titanium dental implants: surface alteration and attempted sterilization. Int J Oral Maxillofac Implants 1992; 4: 441-9.

7. Pick RM, Using lasers in clinical dental practice. J Am Dent Assoc 1993; 124

8. Chu RT, Watanabe L, White JM, Marshall SJ, Hutton JE. Temperature rise and surface modification of lased Titanium cylinders (abstract). J Dent Res 1992; 71: 312
9. Pick RM, Pecaro BC, Silberman CJ. The laser gingivectomy. The use of the $\mathrm{CO}_{2}$ laser for the removal of phenytoin hyperplasia. J Periodontal 1985; 56: 492-6.

10. Fisher SE, Frame JW. The effects of the carbon dioxide surgical laser on oral tissues. $\mathrm{Br} \mathrm{J}$ Oral Maxillofac Surg 1984; 22: 414-425.

11. Arashiro DS, Rapley JW, Cobb CM, Killoy WJ. Histologic evaluation of porcine skin incisions produced by $\mathrm{CO}_{2}$ laser, electrosurgery and scalpel. The Int Jou of Periodontics and Res Dent 1996; 16 : 486-491. 